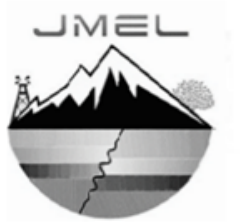

\title{
Pengelolaan Mata Air Karst Sebagai Sumber Air Domestik Di Dusun Duwet, Desa Purwodadi, Kecamatan Tepus, Gunung Kidul, D.I. Yogyakarta
}

\author{
Mufi Bustomi Anam 1, a), Sari Bahagiarti Kusumayudha ${ }^{2)}$, Andi Renata Ade Yudono ${ }^{1)}$ \\ 1) Teknik Lingkungan, Fakultas Teknologi Mineral, UPN "Veteran" Yogyakarta \\ 2) Teknik Geologi, Fakutas Teknologi Mineral, UPN "Veteran" Yogyakarta \\ a) Email korespondensi: mufibustomianam@gmail.com
}

\begin{abstract}
ABSTRAK
Air merupakan salah satu kebutuhan pokok bagi kehidupan manusia. Dusun Duwet, Desa Purwodadi termasuk kawasan bentang alam karst yang memiliki tingkat kelangkaan air tinggi. Pada daerah tersebut terdapat tiga mata air yang mengalir sepanjang tahun, namun pada musim kemarau debit mata air mengalami penurunan kuantitas. Tujuan penelitian ini yaitu menyusun cara pengelolaan mata air pada daerah karst untuk digunakan sebagai sumber air domestik. Metode penelitian yang digunakan yaitu survei dan pemetaan lapangan, matematis dengan menghitung debit mata air dan volume bak penampung, evaluasi, dan wawancara. Karakteristik mata air yang dikaji meliputi sebaran dan tipe mata air berdasarkan debit. Potensi mata air diketahui dari kuantitas dan kualitas air. Hasil penelitian menunjukkan bahwa ketiga mata air termasuk tipe perlapisan/kontak antara satuan batugamping terumbu dan dasit yang memiliki perbedaan porositas dan permeabilitas, dengan sifat pengaliran menahun (perenial springs). Berdasarkan kelas debit mata air Kaliwonosari dan Kaliduren termasuk kelas sedang, sedangkan Luweng Nglibeng termasuk kelas tinggi. Secara umum kualitas air pada ketiga mata air baik untuk digunakan keperluan domestik sehari-hari. Pengelolaan mata air dilakukan secara teknik dengan pembuatan teras bangku dan sarana Perlindungan Mata Air (PMA) dengan pendekatan berbasis masyarakat dan pemerintah.
\end{abstract}

Kata kunci: karakteristik; karst; mata air; pengelolaan; potensi

\begin{abstract}
Water is a principal thing for humans. Duwet Hamlet, Purwodadi Village is a karst landform that subjected to high water scarcity. There are three springs in the research area that flow throught the year, but in the dry season the springs discharge decreases in quantity. The purpose of this study was to arrange management methods springs in the karst area to be used as domestic water sources. The research methods used were field survey and mapping, mathematically by calculating springs flowrate and container volume, evaluation, and interview. The characteristics of the springs that have been studied include the distribution and type of spring based on their discharge. The potential of springs was known from the quantity and quality of water. Based on the results showed that the type of all three springs were included in the type of bedding/contact between the reef limestone and dacitic units which had differences in porosity and permeability, with chronic drainage properties (perenial springs). Based on the discharge classification, Kaliwonosari and Kaliduren springs are classified into moderate class, while Luweng Nglibeng spring belongs to high class. In general, water quality of all three springs is good for daily domestic use. Technically, the management of springs can be done by making bench terraces and Spring Protection Facilities (PMA) by involving community and goverment approaches.
\end{abstract}

Keywords: characteristics; karst; management; potential; springs

\section{PENDAHULUAN}

Air adalah sumber kehidupan yang penting bagi makhluk hidup. Seiring dengan bertambahnya jumlah penduduk, kebutuhan akan air bersih setiap tahun diperkirakan terus meningkat sedangkan jumlah air di bumi adalah tetap. Menurut Danaryanto, dkk. (2005) dalam Riastika (2012) konservasi airtanah adalah upaya melindungi dan memelihara keberadaan, kondisi dan lingkungan airtanah guna mempertahankan kelestarian atau kesinambungan ketersediaan dalam kuantitas dan kualitas yang memadai, demi kelangsungan fungsi dan kemanfaatannya untuk memenuhi kebutuhan makhluk hidup, baik waktu sekarang maupun generasi yang akan datang.

Daerah penelitian termasuk dalam wilayah administrasi Dusun Duwet, Desa Purwodadi, Kecamatan Tepus, Kabupaten Gunung Kidul, Daerah Istimewa Yogyakarta. Secara astronomis, daerah penelitian terletak pada koordinat UTM (Universal Transverse Mercator) 465400 - $466600 \mathrm{mT}$ dan 9096800 - $9098000 \mathrm{mU}$ dengan luas wilayah penelitian 93 ha, merupakan salah satu jalur wisata menuju Pantai Banyu Tibo terletak disebelah timur Pantai Siung yang termasuk 
dalam kawasan Geopark Gunungsewu. Menurut Kusumayudha, dkk. (2015) Gunungsewu adalah medan karst yang menunjukkan fenomena geomorfologi unik yang terdiri dari batugamping Formasi Wonosari. Secara umum geomorfologi Gunungsewu dapat diklasifikasikan dalam dua kelompok bentuklahan, pertama adalah relief positif dan yang kedua relief negatif. Relief positif termasuk bukit kerucut, kubah, punggungan. Sedangkan relief negatif meliputi goa, luweng, doline, uvala, lokva, dan polje. Berdasarkan Peta Kerawanan Bencana Gunung Kidul, daerah tersebut memiliki tingkat kelangkaan air tinggi. Mata air di daerah tersebut diperkirakan cukup untuk memenuhi kebutuhan warga pada musim kemarau walaupun dengan debit mata air lebih kecil dibandingkan pada waktu musim penghujan. Namun masih terdapat warga yang membeli air dari truk tangki khususnya pada waktu musim kemarau panjang. Oleh karena itu, perlu dilakukan pengelolaan mata air yang tepat dengan mengetahui karakteristik mata air dan potensinya dalam memenuhi kebutuhan domestik agar dapat dimanfaatkan secara efektif dan efisien. Peta administrasi daerah penelitian disajikan pada Gambar 1.

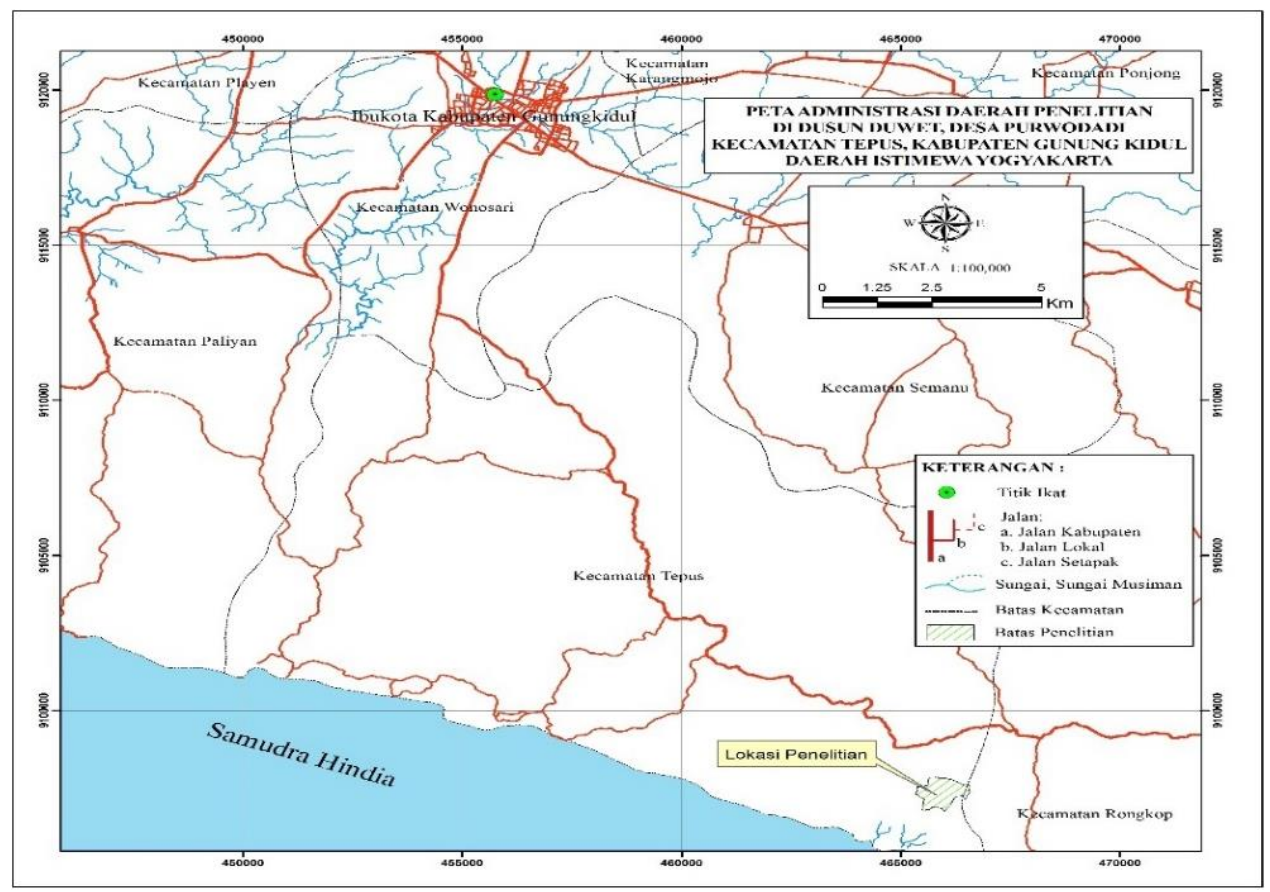

Gambar 1. Peta Administrasi Daerah Penelitian

Tujuan penelitian ini selain melakukan pemetaan geologi dan mengidentifikasi keberadaan mata air juga mengkaji kuantitas dan kualitas air kemudian menyusun cara pengelolaan mata air dengan melakukan perancangan desain Perlindungan Mata Air (PMA).

\section{METODE}

Penelitian ini dilakukan dengan menggunakan data primer dan sekunder. Data primer merupakan data hasil pengukuran dan pengamatan secara langsung di lapangan, sementara data sekunder merupakan data yang diperoleh dari berbagai sumber yang berkaitan dengan penelitian. Metode yang digunakan dalam penelitian meliputi metode survei dan pemetaan lapangan, metode matematis dengan menghitung debit mata air dan volume bak penampung, metode evaluasi, dan metode wawancara. Selain itu untuk mengetahui kualitas mata air maka dilakukan uji kualitas air di laboratorium.

Pemetaan bentuklahan dan kemiringan lereng dengan melakukan interpretasi pada peta topografi kemudian menentukan kelas kemiringan lereng berdasarkan pada klasifikasi Van Zuidam, 1985 dalam Firmansyah, dkk., 2016. Pemetaan satuan batuan dan struktur geologi mengacu pada peta geologi Lembar Surakarta-Giritontro Skala 1 : 100.000 menurut Surono, dkk., 1992. Pemetaan jenis tanah mengacu pada peta jenis tanah Kabupaten Gunung Kidul dengan mengamati tekstur tanah kemudian dianalisis berdasarkan selidik cepat ciri tanah di lapangan menurut Notohadiprawiro (1983). Pemetaan bentuklahan dan kemiringan lereng, satuan batuan dan struktur geologi, dan tekstur tanah digunakan untuk menentukan karakteristik dan arahan konservasi mata air.

Pengambilan sampel air dilakukan pada tiga mata air yang terdapat di Dusun Duwet yaitu Mata Air Kaliduren, Kaliwonosari, dan Luweng Nglibeng kemudian diuji pada laboratorium untuk mengetahui kualitas air. Komponen kualitas air terdiri dari hidrofisika, hidrokimia, dan hidrobiologi (Kusumayudha, 2004). Pengukuran debit Mata Air 
Kaliwonosari dan Kaliduren menggunakan prinsip metode volumetrik, sedangkan pada Mata Air Luweng Nglibeng pengukuran debit dilakukan menggunakan prinsip metode velocity karena dilakukan pada aliran sungai bawah tanah. Besar kebutuhan air penduduk dan jenis penggunaan air diketahui dengan wawancara. Evaluasi karakteristik mata air untuk mengetahui sebaran, tipe, kuantitas dan kualitas mata air. Tipe mata air dianalisis berdasarkan sifat pengairan dan debit mata air. Klasifikasi debit mata air disajikan pada Tabel 1.

Tabel 1. Klasifikasi Debit Mata Air

\begin{tabular}{llll}
\hline Kelas & $\mathrm{m}^{3} /$ detik & Liter/detik & $\mathrm{ml} /$ detik \\
\hline I & $>10$ & $>1000$ & $>10000000$ \\
II & $1-10$ & $1000-10000$ & $1000000-10000000$ \\
III & $0,1-1$ & $100-1000$ & $100000-1000000$ \\
IV & $0,01-0,1$ & $10-100$ & $10000-100000$ \\
V & $0,001-0,01$ & $1-10$ & $1000-10000$ \\
VI & $0,0001-0,001$ & $0,1-1$ & $100-1000$ \\
VII & $0,00001-0,0001$ & $0,01-0,1$ & $10-100$ \\
VIII & $<0,00001$ & $0,001-0,01$ & $<10$ \\
\hline
\end{tabular}

Sumber: Meinzer, 1923 dalam Todd, 1980 dalam Said dan Sudarmadji, 2014.

Iklim di daerah penelitian ditentukan menggunakan klasifikasi Mohr yang disempurnakan oleh Schmidt dan Ferguson (1951) dalam Tjasyono, B (2004). Data iklim digunakan untuk mengetahui tipe mata air berdasarkan sifat pengairan.

- $\quad$ BB : Bulan Basah

- $\quad$ BK : Bulan Kering

- BL : Bulan Lembab

$$
\begin{aligned}
& : \mathrm{P}>100 \mathrm{~mm} / \text { bulan; } \mathrm{P}>\mathrm{E} \\
& : \mathrm{P}<60 \mathrm{~mm} / \text { bulan; } \mathrm{P}<\mathrm{E} \\
& : 60>\mathrm{P}<100 \mathrm{~mm} / \text { bulan }
\end{aligned}
$$$$
Q=\frac{\text { Jumlah rata-rata bulan kering }}{\text { Jumlah rata-rata bulan basah }}
$$

Schmidt dan Ferguson menggolongkan iklim dengan menggunakan rasio Q, yaitu perbandingan antara jumlah rerata bulan kering dengan jumlah rerata bulan basah (Tyasyono, 2004). Tipe Iklim dapat dilihat pada Tabel 2.

Tabel 2. Tipe Iklim Menurut Schmidt - Ferguson

\begin{tabular}{lll}
\hline Tipe Iklim & Nilai Q & Keterangan \\
\hline A & $0-0,143$ & Sangat basah \\
B & $0,143-0,333$ & Basah \\
C & $0,333-0,6$ & Agak basah \\
D & $0,6-1$ & Sedang \\
E & $1-1,67$ & Agak kering \\
F & $1,67-3$ & Kering \\
\hline G & $3-7$ & Sangat kering \\
H & $>7$ & Ekstrim \\
\hline
\end{tabular}

Sumber: Lakitan (2002) dalam Sasminto, dkk. (2014). 
60 ISSN 2549-7197 (cetak), ISSN 2549-564X (online)

JMEL, Volume 4 Nomor 2, 2020

Parameter geofisik digunakan untuk menentukan tingkat kesesuaian lahan untuk tujuan pembangunan bak penampung. Diantara parameter tersebut adalah kemiringan lereng, tekstur tanah, dan penggunaan lahan yang disajikan pada Tabel 3, 4, dan 5 .

Tabel 3. Kriteria dan Harkat Kemiringan Lereng

\begin{tabular}{lll}
\hline No & Klasifikasi & $\begin{array}{l}\text { Sudut Kemiringan } \\
\text { Lereng }(\%)\end{array}$ \\
\hline 1 & Datar/hampir datar & $0-2$ \\
2 & Landai & $2-7$ \\
3 & Miring & $7-15$ \\
4 & Agak curam & $15-30$ \\
5 & Curam & $30-70$ \\
\hline
\end{tabular}

Sumber: Van Zuidam, 1985 dalam Firmansyah, C., dkk., 2016.

Tabel 4. Kriteria Harkat dan Tekstur Tanah

\begin{tabular}{lll}
\hline No & Tekstur Tanah & $\begin{array}{l}\text { Intensitas } \\
\text { Kepentingan } \\
\text { Derajad Nilai }\end{array}$ \\
\hline 1 & Pasir & Sangat besar \\
2 & Pasir geluhan & Besar \\
3 & Geluh & Sedang \\
4 & Lempung pasiran & Kecil \\
\hline 5 & Lempung & Sangat Kecil \\
\hline
\end{tabular}

Sumber: Arsyad, 1989.

Tabel 5. Jenis Penggunaan Lahan

\begin{tabular}{lll}
\hline No & $\begin{array}{l}\text { Jenis Penggunaan } \\
\text { Lahan }\end{array}$ & Derajad Nilai \\
\hline 1 & Sawah, lahan terbuka & Sangat besar \\
2 & Permukiman & Besar \\
3 & Semak belukar & Sedang \\
4 & Perkebunan & Kecil \\
\hline 5 & Hutan & Sangat Kecil \\
\hline
\end{tabular}

Sumber: Paimin, dkk., 2009. 
Volume bak penampung ditentukan berdasarkan Peraturan Menteri Pekerjaan Umum No. 1 Tahun 2009 Tentang Penyelenggaraan Pengembangan SPAM Bukan Jaringan Perpipaan, dengan debit maksimum mata air dan waktu tinggal minimum 10 menit. Kriteria volume bak penampung dapat dilihat pada Tabel 6.

Tabel 6. Volume Bak Penampung

\begin{tabular}{lllll}
\hline $\begin{array}{l}\text { Pelayanan } \\
\text { Orang }\end{array}$ & $\begin{array}{l}\text { Debit } \\
<0,5 \mathrm{~L} / \text { detik }\end{array}$ & $\begin{array}{l}\text { Debit } \\
0,5-0,6 \mathrm{~L} / \text { detik }\end{array}$ & $\begin{array}{l}\text { Debit } \\
0,7-0,8 \mathrm{~L} / \text { detik }\end{array}$ & $\begin{array}{l}\text { Debit } \\
>0,8 \mathrm{~L} / \text { detik }\end{array}$ \\
\hline $200-300$ & $5 \mathrm{~m}^{3}$ & $2 \mathrm{~m}^{3}$ & $2 \mathrm{~m}^{3}$ & $2 \mathrm{~m}^{3}$ \\
$300-400$ & $10 \mathrm{~m}^{3}$ & $5 \mathrm{~m}^{3}$ & $2 \mathrm{~m}^{3}$ & $2 \mathrm{~m}^{3}$ \\
$400-500$ & $10 \mathrm{~m}^{3}$ & $10 \mathrm{~m}^{3}$ & $5 \mathrm{~m}^{3}$ & $2 \mathrm{~m}^{3}$ \\
\hline
\end{tabular}

Sumber: Permen PU No. 1 Tahun 2009.

\section{HASIL DAN PEMBAHASAN}

\subsection{Kondisi Geologis}

Pada peta geologi lembar Surakarta-Giritontro Jawa menurut Surono, dkk., (1992), litologi penyusun daerah penelitian termasuk dalam Formasi Wonosari-Punung. Formasi tersebut terdiri atas batugamping, batugamping napal-tuffan, batugamping konglomeratan, batupasir tuffan, dan batulanau. Namun berdasarkan hasil pengamatan dan pemetaan di daerah penelitian didapatkan satuan batuan beku dasit, hal tersebut juga diperkuat oleh penelitian yang dilakukan oleh Hartono dan Bronto (2007). Satuan dasit pada daerah penelitian berasal dari intrusi magma yang tersingkap di permukaan. Menurut Bronto (2010) Formasi Wonosari-Punung berada pada umur geologi periode Tersier pada kala Miosen Tengah - Atas. Hubungan stratigrafi daerah penelitian dapat dilihat pada Gambar 2.

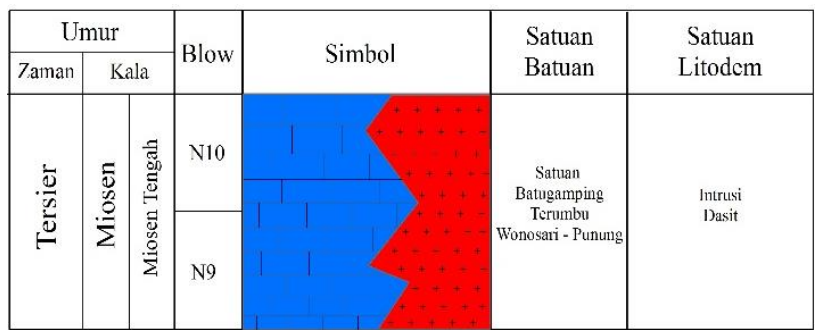

Gambar 2. Kolom Hubungan Stratigrafi Lokal Daerah Penelitian

Sumber: Bronto, 2010 Dengan Modifikasi Fitur Litologi Oleh Penulis, 2018

Lokasi penelitian merupakan daerah karst yang karakteristik topografi dan sistem drainase khas akibat batuan yang mudah larut dalam air. Karst di daerah penelitian dicirikan dengan kenampakan di atas permukaan seperti doline, ponor, lapies, diaklas, dan bukit karst dengan bentuk kerucut dan punggungan. Sedangkan kenampakan karst di bawah permukaan dicirikan dengan terdapatnya luweng vertikal (vertikal shaft) dan sungai bawah tanah. Daerah penelitian memiliki karakteristik akuifer khas dengan sistem drainase bawah permukaan yang dipengaruhi oleh sifat dari batuan penyusunnya. Batuan penyusun berupa batugamping terumbu pada daerah penelitian memiliki porositas sekunder mengalami proses pelarutan oleh air yang masuk melalui rekahan-rekahan (diaklas) dan berkembang membentuk saluran-saluran air bawah permukaan. Terdapatnya satuan batuan dasit menyebabkan mata air dapat muncul di permukaan oleh akibat kontak batuan yang berbeda porositas dan permeabilitasnya. Peta persebaran satuan batuan di daerah penelitian disajikan pada Gambar 3. 


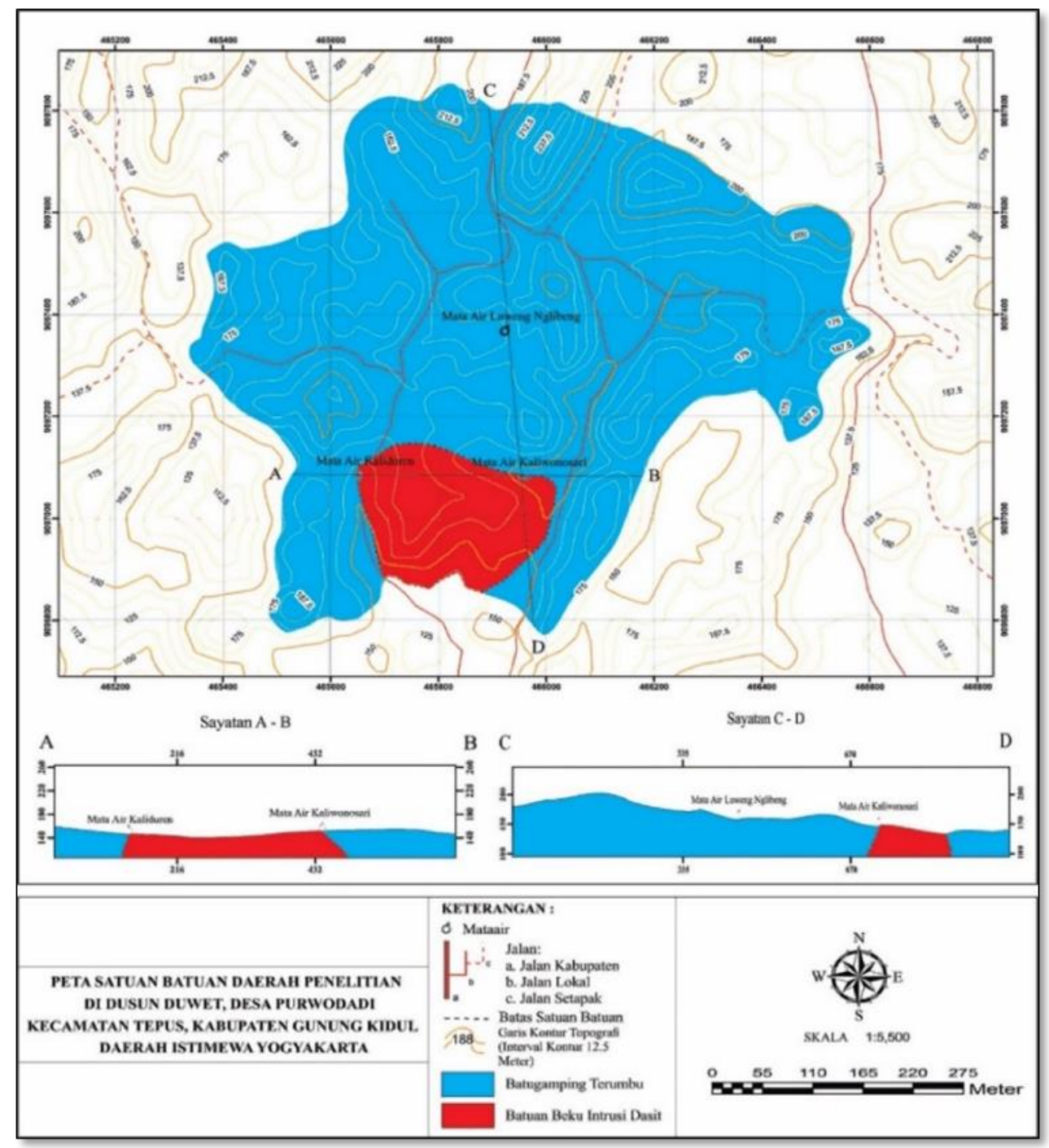

Gambar 3. Peta Satuan Batuan Daerah Penelitian

\subsection{Karakteristik Mata Air (sebaran, tipe, dan kualitas air)}

Di daerah penelitian terdapat 3 mata air yang digunakan untuk kebutuhan domestik yaitu Mata Air Kaliwonosari, Kaliduren, dan Luweng Nglibeng dengan persebaran tidak berada pada jenis batuan yang sama. Mata Air Kaliwonosari dan Kaliduren berada pada daerah kontak antara satuan batugamping terumbu dan satuan dasit, sedangkan Mata Air Luweng Nglibeng berada pada satuan batugamping terumbu.

Berdasarkan klasifkasi debit oleh Meinzer (1923) dalam Todd (1980) dalam Said, N.F., dan Sudarmadji (2014), mata air Kaliwonosari dan Kaliduren termasuk dalam kategori kelas VI dengan debit antara 0,1 - 1 liter/detik. Sedangkan mata air Luweng Nglibeng masuk dalam kategori kelas III dengan debit antara 100 - 1000 liter/detik. Pengukuran debit mata air dilakukan selama 3 bulan yaitu pada bulan Januari, Februari, dan Maret. Debit terendah ketiga mata air tersebut terjadi pada bulan Maret dengan debit Mata Air Kaliwonosari sebesar 0,366 liter/detik, Kaliduren sebesar 0,126 liter/detik, dan Luweng Nglibeng sebesar 164 liter/detik. Besar debit ketiga mata air tersebut dipengaruhi oleh intensitas hujan yang terjadi, semakin tinggi curah hujan yang terjadi maka semakin besar pula debit yang dikeluarkan oleh mata air. Kondisi ketiga mata air dapat dilihat pada Gambar 4. 


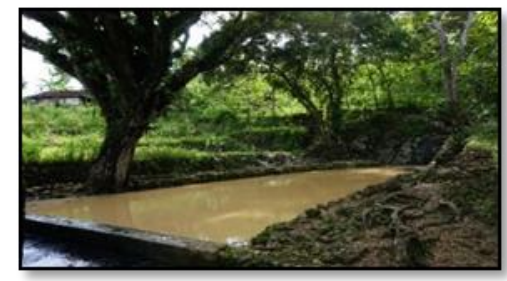

(a)

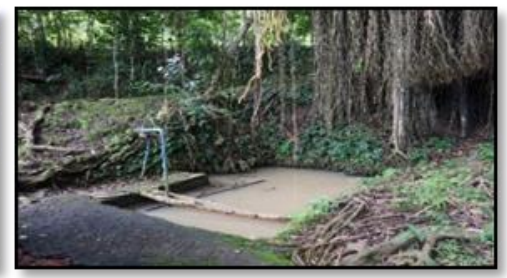

(b)

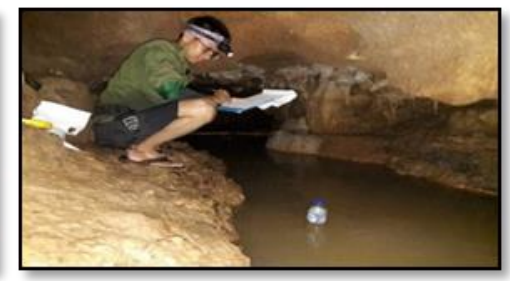

(c)

Gambar 4. Sumber Air Permukaan (a) Mata Air Kaliwonosari (b) Mata Air Kaliduren, Sumber Air Bawah Permukaan (c) Kondisi di Dalam Luweng Nglibeng

Ketiga mata air memiliki tipe perenial springs (mengalir sepanjang tahun), mata air tetap mengeluarkan air pada waktu musim kemaru walaupun mengalami penurunan debit dibandingkan dengan waktu musim penghujan. Periode kemarau pada daerah penelitian rata-rata terjadi selama 5 bulan setiap tahunnya, yaitu antara bulan Mei sampai September. Berdasarkan perhitungan data curah hujan selama 2008 - 2017 memiliki rata-rata bulan basah setiap tahunnya 7,3 bulan, bulan kering 3,9 bulan, dan bulan lembab 0,9 bulan sehingga di dapatkan nilai Q adalah 0,534. Termasuk dalam tipe golongan C (agak basah). Grafik curah hujan di daerah penelitian disajikan pada Gambar 5.

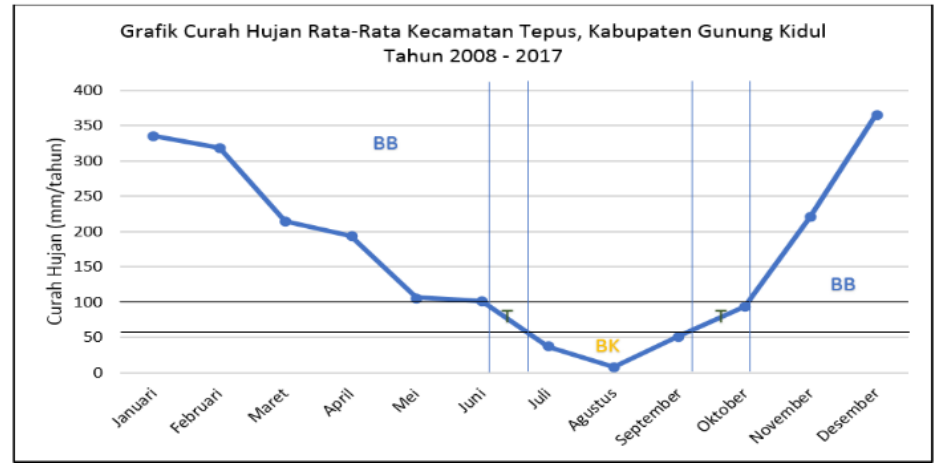

Keterangan $: \mathrm{BK}=$ Bulan Kering, $\mathrm{BB}=$ Bulan Basah, $\mathrm{T}=$ Transisi

Gambar 5. Grafik Curah Hujan Rata-Rata Kecamatan Tepus, Kabupaten Gunung Kidul Tahun 2008 - 2017

Berdasarkan hasil observasi dan pemetaan, lapangan kedua Mata Air Kaliwonosari dan Kaliduren muncul karena adanya kontak antara 2 jenis satuan batuan yang berbeda yaitu satuan batugamping terumbu dari Formasi Wonosari-Punung dan satuan dasit (intrusi) yang berada di sebelah selatan daerah penelitian. Perbedaan porositas dan permeabilitas batugamping terumbu dan satuan dasit mengakibatkan mata air Kaliwonosari dan Kaliduren terbentuk. Hal ini menunjukkan bahwa kedua mata air tersebut termasuk dalam tipe mata air perlapisan/kontak (contact springs).

Mata Air Luweng Nglibeng terbentuk oleh rekahan-rekahan akibat proses pelarutan batugamping yang menghasilkan luweng vertikal (vertikal shaft) sedalam 16,1 meter. Kontak dari satuan batugamping terumbu dengan batuan beku yang memiliki sifat impermeabel atau kedap air, menyebabkan munculnya mata air yang mengalir menjadi sungai bawah tanah. Model pembentukan mata air di daerah penelitian dapat dilihat pada Gambar 6.

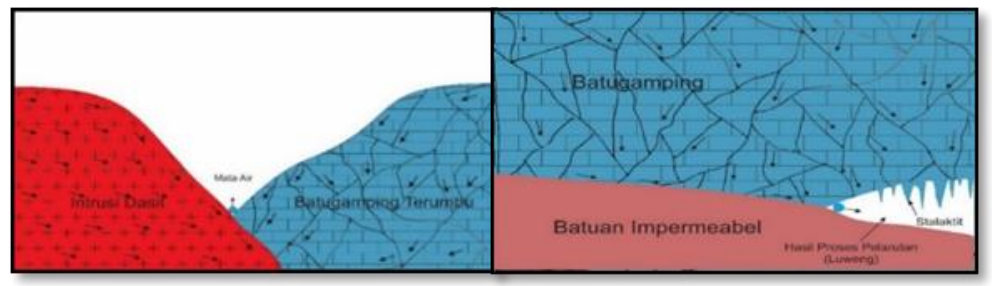

(a)

(b)

Gambar 6. (a) Model Pembentukan Mata Air Kaliduren dan Mata Air Kaliwonosari (b) Model Pembentukan Mata Air Luweng Nglibeng

Berdasarkan hasil uji laboratorium yang dilakukan di Balai Pengujian, Informasi Permukiman dan Bangunan dan Pengembangan Jasa Konstruksi (BALAI PIPBPJK), Dinas Pekerjaan Umum, Perumahan Dan Energi Sumber Daya 
Mineral Daerah Istimewa Yogyakarta, secara umum kualitas ketiga mata air baik dan layak dikonsumsi. Dari 13 parameter kualitas air yang diujikan berdasarkan Permenkes RI No. 32 Tahun 2017 dan Pergub DIY No. 20 Tahun 2008 secara garis besar berada dibawah ambang batas baku mutu. Namun, parameter kekeruhan Mata Air Kaliwonosari, dan Total Coliform pada Mata Air Kaliduren dan Luweng Nglibeng masih melebihi ambang batas baku mutu. Kekeruhan pada Mata Air Kaliwonosari disebabkan oleh bak penampung mata air yang kurang optimal sehingga air tercampur dengan material endapan tanah. Untuk mengantisipasi hal tersebut maka dalam pengambilan air sebaiknya dilakukan di dekat sumber tempat pemunculan mata air karena belum terkontaminasi oleh sedimen tanah. Total Coliform pada Mata Air Kaliduren dan Luweng Nglibeng dapat diturunkan kadarnya dengan cara dimasak terlebih dahulu sebelum dikonsumsi. Hasil uji laboratorium kualitas air di daerah penelitian disajikan pa da Tabel 7.

Tabel 7. Hasil Uji Laboratorium Kualitas Air

\begin{tabular}{|c|c|c|c|c|c|c|}
\hline Parameter & Satuan & $\begin{array}{l}\text { Mata Air } \\
\text { Kaliwonosari }\end{array}$ & $\begin{array}{l}\text { Mata Air } \\
\text { Kaliduren }\end{array}$ & $\begin{array}{l}\text { Mata Air } \\
\text { Nglibeng }\end{array}$ & $\begin{array}{l}\text { Baku Mutu } \\
\text { Permenkes RI } \\
\text { No. } 322017\end{array}$ & $\begin{array}{l}\text { Baku Mutu } \\
\text { Pergub DIY } \\
\text { No. } 202008\end{array}$ \\
\hline $\mathrm{Bau}$ & - & Tdk berbau & Tdk berbau & Tdk berbau & Tdk berbau & Tdk berbau \\
\hline Rasa & - & Tdk berasa & Tdk berasa & Tdk berasa & Tdk berasa & - \\
\hline Kekeruhan & Skala NTU & 26,2 & 3,12 & 25 & 25 & 5 \\
\hline $\mathrm{pH}$ & $\mathrm{mg} / \mathrm{L}$ & 7,3 & 6,7 & 7,50 & $6,5-8,5$ & $6-8,5$ \\
\hline TDS & $\mathrm{mg} / \mathrm{L}$ & 82 & 162 & 196 & 1000 & 1000 \\
\hline Kesadahan $\left(\mathrm{CaCO}_{3}\right)$ & $\mathrm{mg} / \mathrm{L}$ & 14,4 & 111,6 & 172,80 & 500 & - \\
\hline Magnesium (Mg) & $\mathrm{mg} / \mathrm{L}$ & 0,07 & 8,75 & 26,24 & - & - \\
\hline Kalsium (Ca) & $\mathrm{mg} / \mathrm{L}$ & 1,6 & 35,2 & 33,6 & - & - \\
\hline Nitrat $\left(\mathrm{NO}^{3}\right)$ & $\mathrm{mg} / \mathrm{L}$ & 1,71 & 1,22 & 2,40 & 10 & 10 \\
\hline Nitrit (NO2-) & $\mathrm{mg} / \mathrm{L}$ & 0,03 & 0,05 & 0,003 & 1 & 0,06 \\
\hline Besi $(\mathrm{Fe})$ & $\mathrm{mg} / \mathrm{L}$ & 0,20 & 0,12 & 0,02 & 1 & 0,3 \\
\hline Klorida $\left(\mathrm{Cl}^{-}\right)$ & $\mathrm{mg} / \mathrm{L}$ & 19,4 & 11,5 & 12,44 & - & 600 \\
\hline COD & $\mathrm{mg} / \mathrm{L}$ & 9,82 & 7,0 & 5,93 & - & 10 \\
\hline BOD & $\mathrm{mg} / \mathrm{L}$ & 3,84 & 1,92 & 1,92 & - & 2 \\
\hline Total Coliform & JPT/100 mL & $4 \times 10$ & $7 \times 10$ & $11 \times 10^{2}$ & 50 & $1000 \mathrm{MPN}$ \\
\hline
\end{tabular}

Sumber: Hasil Uji Laboratorium Kualitas Air Balai PIPBPJK, 2018.

\subsection{Potensi Mata Air}

Hasil perhitungan menunjukkan rata-rata debit Mata Air Kaliwonosari adalah 84.643,2 liter/hari, debit Mata Air Kaliduren adalah 17.452,8 liter/hari, dan debit Mata Air Luweng Nglibeng adalah 26.467.200 liter/hari. Total rata-rata kebutuhan air domestik warga Dusun Duwet adalah 5.919 liter/hari. Hal tersebut menunjukkan bahwa ketersediaan air pada ketiga mata air tersebut mengalami surplus atau mencukupi kebutuhan warga setiap tahun. Hasil pengukuran debit ketiga mata air di daerah penelitian disajikan pada Tabel 8, 9, dan 10.

Tabel 8. Hasil Pengukuran Debit Mata Air Kaliwonosari

\begin{tabular}{llll}
\hline No & Bulan & liter/detik & liter/hari \\
\hline 1 & Januari & 0,643 & $55.555,22$ \\
2 & Februari & 1,95 & 166.752 \\
3 & Maret & 0,366 & $31.622,2$ \\
& Rata-Rata & 0,986 & $84.643,2$ \\
\hline
\end{tabular}


Tabel 9. Hasil Pengukuran Debit Mata Air Kaliduren

\begin{tabular}{lllc}
\hline No & Bulan & liter/detik & liter/hari \\
\hline 1 & Januari & 0,176 & $15.206,4$ \\
2 & Februari & 0,304 & $26.265,6$ \\
3 & Maret & 0,126 & $10.886,4$ \\
& Rata-Rata & 0,202 & $17.452,8$ \\
\hline
\end{tabular}

Tabel 10. Hasil Pengukuran Debit Mata Air Luweng Nglibeng

\begin{tabular}{llll}
\hline No & Bulan & liter/detik & liter/hari \\
\hline 1 & Januari & 578 & 49.939 .200 \\
2 & Februari & 177 & 15.292 .800 \\
3 & Maret & 164 & 14.169 .600 \\
\hline & Rata-Rata & 306,333 & 26.467 .200 \\
\hline
\end{tabular}

\subsection{Perlindungan Mata Air (PMA)}

Perlindungan Mata Air (PMA) merupakan bangunan atau kontruksi untuk melindungi sumber mata air terhadap pencemaran yang dilengkapi dengan bak penampung dengan bentuk tidak mengikat dan disesuaikan dengan topografi dan situasi mata air. Parameter yang digunakan untuk menentukan lokasi Perlindungan Mata Air (PMA) diantaranya adalah kemiringan lereng, tekstur tanah, dan penggunaan lahan. Kemiringan lereng sangat berpengaruh terhadap pembangunan PMA. Pada kemiringan lereng yang curam tidak memungkinkan untuk dibangun PMA. Tekstur tanah juga menjadi perhatian karena tekstur tanah yang labil dapat memicu gerakan massa tanah, sehingga mengancam keberadaan bangunan PMA. Selain itu, penggunaan lahan merupakan faktor penting dalam pembangunan PMA. Perencanaan bangunan harus melihat aspek sosial sehingga akan lebih baik dibangun di dekat permukiman agar mobilitas warga dalam penggunaan air tidak terdapat kendala yang berarti. Parameter penentuan lokasi Perlindungan Mata Air (PMA) dapat dilihat pada Tabel 11, 12, dan 13.

Tabel 11. Kemiringan Lereng dan Harkat di Daerah Penelitian

\begin{tabular}{llllll}
\hline No & Klasifikasi & Harkat & Keterangan & Luas (ha) & Persentase \\
\hline 1 & Datar/hampir datar & 5 & Sangat Baik & 3,489 & $2,6 \%$ \\
2 & Landai & 4 & Baik & 13,012 & $13,12 \%$ \\
3 & Miring & 3 & Sedang & 38,25 & $42,12 \%$ \\
4 & Agak curam & 2 & Tidak baik & 34,291 & $37,9 \%$ \\
5 & Curam & 1 & Sangat tidak baik & 3,958 & $4,25 \%$ \\
\hline
\end{tabular}


66 ISSN 2549-7197 (cetak), ISSN 2549-564X (online)

JMEL, Volume 4 Nomor 2, 2020

Tabel 12. Tekstur Tanah dan Harkat di Daerah Penelitian

\begin{tabular}{llllll}
\hline No & Tekstur & Harkat & Keterangan & Luas (ha) & Persentase \\
\hline 1 & Pasir & 5 & Sangat Baik & 0 & $0 \%$ \\
\hline 2 & Pasir geluhan & 4 & Baik & 85,9 & $92,36 \%$ \\
3 & Geluh & 3 & Sedang & 0 & $0 \%$ \\
\hline 4 & Lempung pasiran & 2 & Tidak baik & 7,1 & $7,64 \%$ \\
5 & Lempung & 1 & Sangat tidak baik & 0 & $0 \%$ \\
\hline
\end{tabular}

Tabel 13. Penggunaan Lahan dan Harkat di Daerah Penelitian

\begin{tabular}{llllll}
\hline No & Jenis Lahan & Harkat & Keterangan & Luas (ha) & Persentase \\
\hline 1 & Sawah, lahan terbuka & 5 & Sangat Baik & 81,75 & $87,9 \%$ \\
2 & Permukiman & 4 & Baik & 11,25 & $12,1 \%$ \\
3 & Semak belukar & 3 & Sedang & 0 & $0 \%$ \\
4 & Perkebunan & 2 & Tidak baik & 0 & $0 \%$ \\
5 & Hutan & 1 & Sangat tidak baik & 0 & $\%$ \\
\hline
\end{tabular}

\subsubsection{Pendekatan Teknik Untuk Pengelolaan Mata Air}

Pendekatan teknik untuk pengelolaan mata air adalah dengan melakukan perawatan bangunan penangkap mata air. Kondisi bangunan penangkap mata air pada daerah penelitian kurang terawat. Oleh karena itu, perlunya kesadaran warga dalam merawat bangunan penangkap mata air. Bangunan penangkap Mata Air Kaliduren dapat dilihat pada Gambar 7.

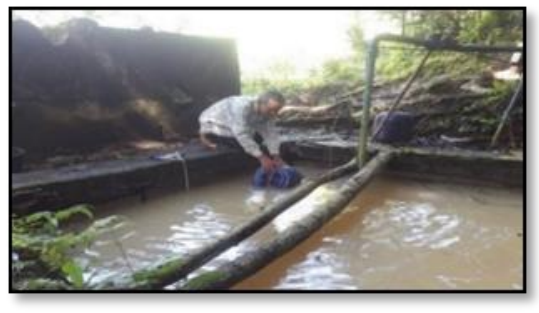

Gambar 7. Kondisi Bangunan Penangkap Mata Air Kaliduren Kurang Terawat Dengan Baik

Perlindungan Mata Air (PMA) dengan perancangan bangunan bak penampung air dan sarana mandi, cuci umum dimaksudkan agar mata air tidak tercemar. Hal itu dikarenakan selama ini warga melakukan pengambilan air langsung dari bak penangkap mata air. Bak penampung air dan sarana mandi, cuci umum dibangun pada lokasi yang memiliki topografi lebih rendah dari Mata Air Kaliwonosari dan Kaliduren. Dimensi ukuran bangunan Perlindungan Mata Air (PMA) disesuaikan dengan kondisi di daerah penelitian. Berdasarkan pengukuran debit mata air maka volume bak penampung mata air yang direkomendasikan yaitu sebesar $2 \mathrm{~m}^{3}$ mengacu pada Peraturan Menteri Pekerjaan Umum Nomor 1 Tahun 2009 Tentang Penyelenggaran Pengembangan SPAM Bukan Jaringan Perpipaan. Sedangkan ukuran total bangunan Perlindungan Mata Air secara keseluruhan yaitu sebesar $36 \mathrm{~m}^{2}$. Desain Bangunan PMA Kaliwonosari dan Kaliduren dapat dilihat pada Gambar 8. 

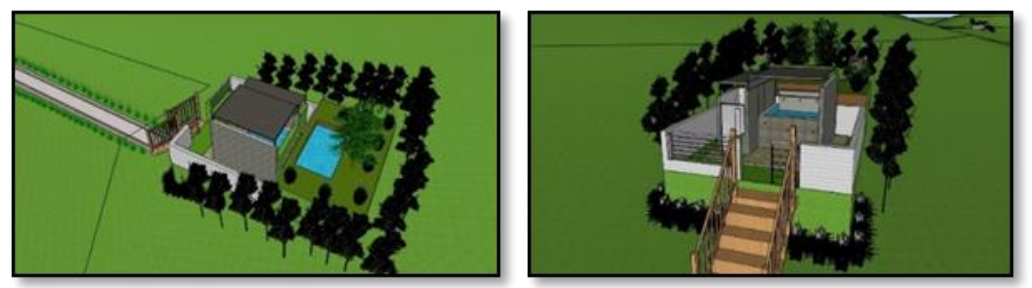

Gambar 8. Desain Bangunan Perlindungan Mata Air (PMA) Kaliwonosari dan Kaliduren

Berdasarkan hasil pengamatan di lapangan Mata Air Kaliwonosari direkomendasikan memiliki volume bak penampung air sebesar $2 \mathrm{~m}^{3}$ dengan luas total bangunan PMA secara keseluruhan yaitu $36 \mathrm{~m}^{2}$. Mata Air Kaliduren direkomendasikan memiliki volume bak penampung sebesar $3 \mathrm{~m}^{3}$ dengan luas total bangunan PMA secara keseluruhan yaitu $42 \mathrm{~m}^{2}$. Sedangkan Mata Air Luweng Nglibeng dimanfaatkan oleh warga dengan cara memompa air dari dalam luweng kemudian ditampung dengan 3 tandon air yang ditempatkan di atas bukit. Total volume tandon air yaitu $13 \mathrm{~m}^{3}$ dan dialirkan langsung menuju rumah warga dengan sistem gravitasi. Namun, cara tersebut masih terdapat kendala salah satunya yaitu warga harus mengantri untuk mendapatkan air secara bergilir. Oleh karena itu perlunya perancangan untuk pembangunan hidran umum. Kondisi tandon penampung Mata Air Luweng Ngibeng dapat dilihat pada Gambar 9.

Hidran umum dalam bentuk tandon penampung air dengan volume $2 \mathrm{~m}^{3}$ ditempatkan pada area permukiman. Penentuan lokasi hidran umum berdasarkan topografi datar sampai landai (1\% - 6\%) dengan elevasi lebih rendah dari tandon penampung Luweng Nglibeng agar dapat disalurkan dengan sistem gravitasi. Desain hidran umum Mata Air Luweng Nglibeng dapat dilihat pada Gambar 10.

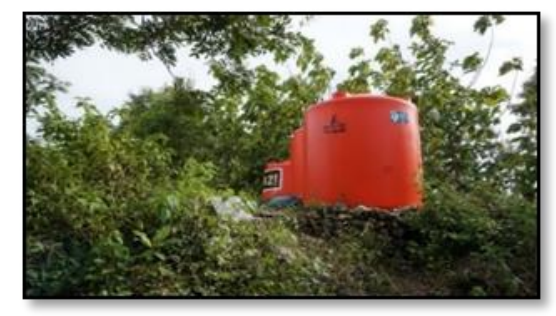

Gambar 9. Tandon Penampung Mata Air Luweng Nglibeng
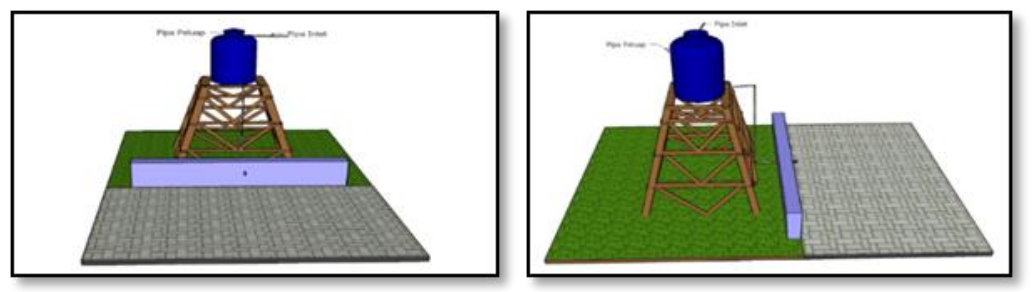

Gambar 10. Hidran Umum Mata Air Luweng Nglibeng

\subsubsection{Pendekatan Teknik Untuk Daerah Imbuhan}

Penentuan daerah imbuhan berdasarkan Permen ESDM Nomor 17 Tahun 2012 disebutkan pada pasal 4 bahwa kawasan bentang alam karst menunjukkan bentuk eksokarst dan endokarst memiliki fungsi sebagai daerah imbuhan air tanah yang mampu menjadi media meresapkan air permukaan ke dalam tanah. Daerah imbuhan adalah daerah resapan air yang mampu menambah airtanah secara alami, sementara daerah lepasan adalah daerah keluaran air tanah yang berlangsung secara alami. Pengelolaan daerah imbuhan di daerah penelitian dilakukan untuk mengendalikan air permukaan (run off) dan mencegah gerakan massa batuan dan/tanah. Pendekatan teknik untuk pengelolaan daerah imbuhan dapat berupa perancangan teras bangku yang disesuaikan dengan kondisi daerah penelitian. Daerah imbuhan terdiri atas penggunaan lahan berupa tegalan/ladang dengan kemiringan lereng miring sampai curam $(10 \%-70 \%)$. Desain teras bangku daerah imbuhan dapat dilihat pada Gambar 11. 
68 ISSN 2549-7197 (cetak), ISSN 2549-564X (online)

JMEL, Volume 4 Nomor 2, 2020
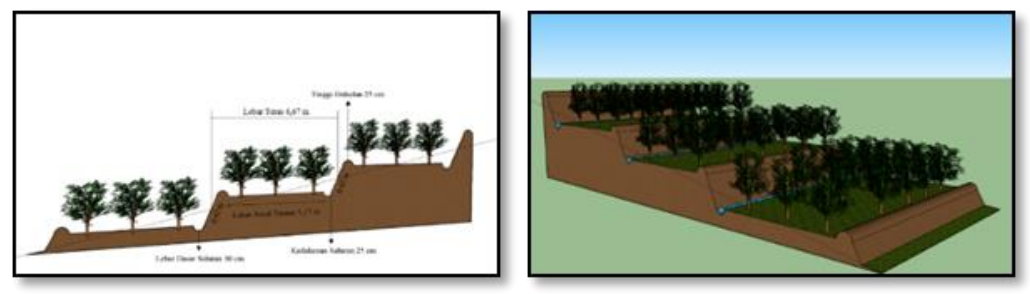

Gambar 11. Teras Bangku Pada Daerah Imbuhan

Pada daerah imbuhan dengan kemiringan lereng 30\% dapat diterapkan sistem teras bangku dengan lebar teras maksimum 6,67 $\mathrm{m}$ dan lebar maksimum areal yang dapat ditanami 5,17 m. Kedalaman potongan maksimum dengan teras yang berada di bawahnya adalah $0,42 \mathrm{~m}$, jumlah tangga teras yang akan dibuat per $100 \mathrm{~m}$ lereng maksimal sebanyak 15 buah teras. Sementara itu teras bangku akan dilengkapi guludan dan saluran air dengan tinggi tumpukan tanah sekitar $25 \mathrm{~cm}$ dan lebar dasar sekitar $30 \mathrm{~cm}$. Fungsi saluran air adalah menampung air yang mengalir dari teras untuk masuk kedalam tanah. Kriteria penggunaan lahan dan harkat di daerah penelitian disajikan pada Tabel 14.

Tabel 14. Penggunaan Lahan dan Harkat di Daerah Penelitian

\begin{tabular}{|c|c|c|c|c|c|c|c|}
\hline Kecuraman Lereng (\%) & 10 & 20 & 30 & 40 & 50 & 60 & 70 \\
\hline Lebar areal yang dapat ditanami (m) & 18,5 & 8,5 & 5,17 & 3,5 & 2,5 & 1,83 & 1,36 \\
\hline Lebar teras $(\mathrm{m})$ & 20 & 10 & 6,67 & 5 & 4 & 3,33 & 2,86 \\
\hline Jumlah teras tangga per $100 \mathrm{~m}$ lereng & 5 & 10 & 15 & 20 & 25 & 30 & 35 \\
\hline $\begin{array}{l}\text { Kedalaman potongan maksimum }(\mathrm{m}), \text { tidak } \\
\text { termasuk saluran pembuangan }\end{array}$ & 0,47 & 0,45 & 0,42 & 0,40 & 0,37 & 0,35 & 0,32 \\
\hline Persentase areal yang dapat ditanami per hektar $(\%)$ & 92,5 & 85 & 77,5 & 70 & 62,5 & 55 & 47,5 \\
\hline Luas muka teras per hektar areal berteras $\left(\mathrm{m}^{2}\right)$ & 994 & 2162 & 3559 & 5253 & 7354 & 10027 & 13545 \\
\hline Volume galian tanah per hektar areal berteras $\left(\mathrm{m}^{3}\right)$ & 1270 & 1335 & 1390 & 1457 & 1540 & 1642 & 1783 \\
\hline
\end{tabular}

Sumber: Constantinesco, 1987 dalam Suripin, 2002 dalam Kodoatie, 2012.

Peta arahan pengelolaan disajikan pada Gambar 12. 


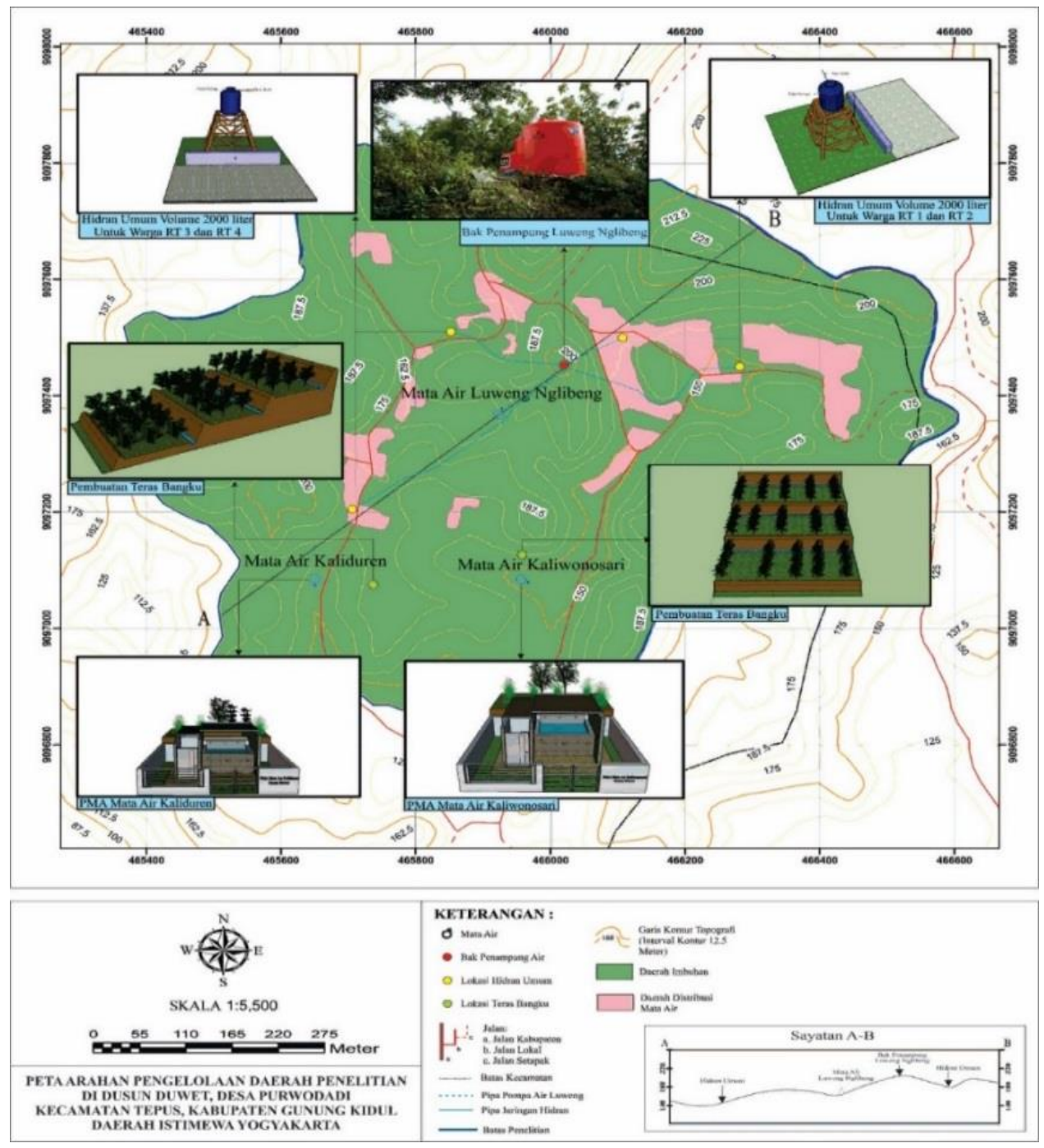

Gambar 12. Peta Arahan Pengelolaan

\section{KESIMPULAN}

Pada daerah penelitian terdapat tiga mata air dengan tipe perenial springs (mengalir sepanjang tahun). Pemunculan mata air Kaliwonosari dan Kaliduren diakibatkan oleh kontak antar satuan batuan yaitu batugamping terumbu formasi Wonosari-Punung dan dasit (intrusi). Sedangkan pemunculan mata air Luweng Nglibeng diakibatkan oleh proses pelarutan batugamping yang membentuk lorong-lorong vertikal maupun horizontal di bawah permukaan tanah.

Potensi mata air untuk pemenuhan kebutuhan domestik cukup tinggi dengan kualitas air tergolong baik. Oleh karena itu perlunya upaya konservasi untuk menjaga keberlangsungan mata air pada daerah karst. Konservasi mata air pada daerah karst meliputi 2 aspek, yaitu dengan melakukan pendekatan teknik untuk pengelolaan mata air maupun daerah imbuhan.

Pengelolaan mata air dengan Perlindungan Mata Air (PMA) mencakup perawatan bak penangkap mata air dan membangun bak penampung air serta sarana mandi cuci, selain itu dengan perancangan hidran umum untuk memaksimalkan potensi dari mata air Luweng Nglibeng. Konservasi pada daerah imbuhan diantaranya dengan pembuatan teras bangku di sekitar mata air yang berfungsi untuk mengendalikan aliran permukaan (run off) dan mencegah gerakan massa tanah/batuan.

Diperlukan peran serta masyarakat dan pemerintah dalam menjaga daerah karst. Dengan karakteristik topografi dan sistem drainase yang khas, karst menyimpan potensi air melimpah di bawah permukaannya. Sehingga kegiatan manusia yang berpotensi menimbulkan dampak antropogenik yang dapat berdampak buruk bagi ekosistem dapat diminimalisir. 
70 ISSN 2549-7197 (cetak), ISSN 2549-564X (online)

JMEL, Volume 4 Nomor 2, 2020

\section{DAFTAR PUSTAKA}

Arsyad, S. (1989). Konservasi Tanah Dan Air. Bogor: IPB.

Bronto, S. (2010). Identifikasi Gunung Api Purba Pendul Di Perbukitan Jiwo, Kecamatan Bayat, Kabupaten Klaten Jawa Tengah. Jurnal Sumber Daya Geologi, 20, 3-13.

Firmansyah, C., Haryanto, I., Yoseph, B., Sunardi, E. (2016). Analisa Kontrol Struktur Geologi Terhadap Morfologi dan Pengaruhnya Dengan Kerentanan Lahan Daerah Kecamatan Rajagaluh, Kabupaten Majalengka Dan Sekitarnya. Prosiding Seminar Nasional Ke-3 Fakultas Teknik Geologi Universitas Padjajaran, 3(2).

Hartono, G. dan Bronto, S. (2007). Asal-Usul Pembentukan Gunung Batur Di Daerah Wediombo, Gunung Kidul, Yogyakarta. Jurnal Geologi Indonesia, 2, 143-158.

Kodoatie, J. R. (2012). Tata Ruang Air Tanah. Yogyakarta: ANDI.

Kusumayudha, S. B. (2004). Mengenal Hidrogeologi Karst. Yogyakarta: Pusat Studi Karst LPPM UPN "Veteran" Yogyakarta.

Kusumayudha, S. B., Setiawan, J., Ciptahening, A. N., Septianta, P. D. (2015). Geomorphologic Model of Gunungsewu Karst, Gunung Kidul Regency, Yogyakarta Special Territory, Indonesia: The Role of Lithologic Variation and Geologic Structure. Jurnal of Geological Resource and Engineering, 1, 1-7.

Notohadiprawiro, T. (1983). Selidik Cepat Ciri Tanah di Lapangan. Jakarta: Ghalia Indonesia.

Paimin, Sukresno, Pramono, B. I. (2009). Teknik Mitigasi Banjir dan Tanah Longsor. Balikpapan: Tropenbos International Indonesia Programme.

Peraturan Gubernur Daerah Istimewa Yogyakarta Tahun 2008 Tentang Baku Mutu Air di Provinsi Daerah Istimewa Yogyakarta.

Peraturan Menteri Kesehatan Nomor 32 Tahun 2017 Tentang Standar Baku Mutu Kesehatan Lingkungan Dan Persyaratan Kesehatan Air Untuk Keperluan Higiene Sanitasi, Kolam Renang, Solus Per Aqua, Dan Pemandian Umum.

Peraturan Menteri Pekerjaan Umum Nomor 1 Tahun 2009 Tentang Penyelenggaraan Pengembangan Sistem Penyediaan Air Minum Bukan Jaringan Perpipaan.

Riastika, M. (2012). Pengelolaan Airtanah Berbasis Konservasi Di Recharge Area Boyolali (Studi Kasus Recharge Area Cepogo, Boyolali, Jawa Tengah), Jurnal Ilmu Lingkungan Program Studi Ilmu Lingkungan Program Pasca Sarjana UNDIP, 9, 86-97.

Said, N. F., dan Sudarmadji. (2014). Kajian Ketersediaan dan Penggunaan Air Dari Mata Air Untuk Kebutuhan Domestik di Kecamatan Turi, Kabupaten Sleman. Jurnal Bumi Indonesia, 3, 1-10.

Sasminto, A. R., Sutanhaji, T. A., Rahadi, B. (2014). Analisis Spasial Penentuan Iklim Menurut Klasifikasi SchmidtFerguson dan Oldeman di Kabupaten Ponorogo. Jurnal Sumber Daya Alam dan Lingkungan, 1, 51-56.

Surono, Toha, B., Sudarno, I. (1992). Peta Geologi Lembar Surakarta-Giritontro Jawa. Bandung: Pusat Penelitian dan Pengembangan Geologi.

Tjasyono, B. (2004). Klimatologi. Bandung: ITB. 